Additional plots of the correlation of frequencies and adsorption energies of $\mathrm{H}_{2}$ at crown-ethers and zeolites

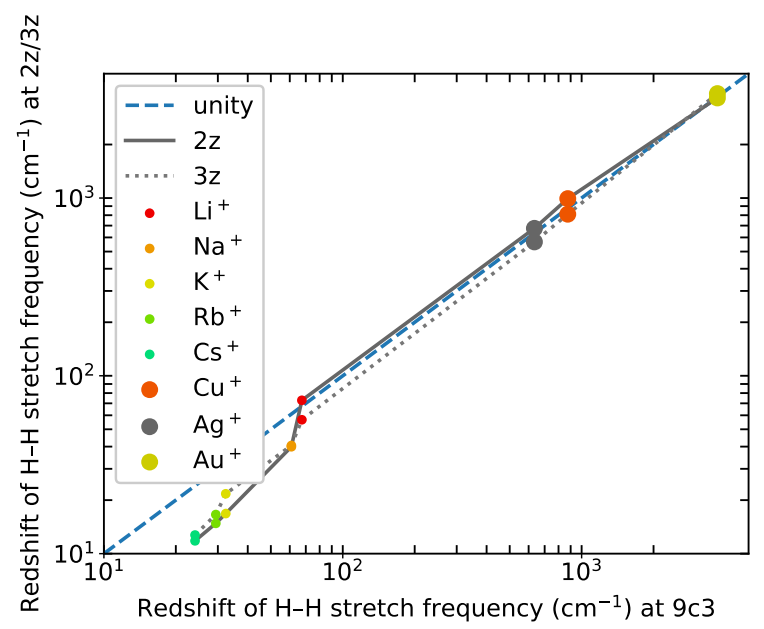

Figure S1. Correlation of the shift of the H-H stretch frequency between the molecular 9-crown-3 model system and the zeolite cluster models in log-log representation.

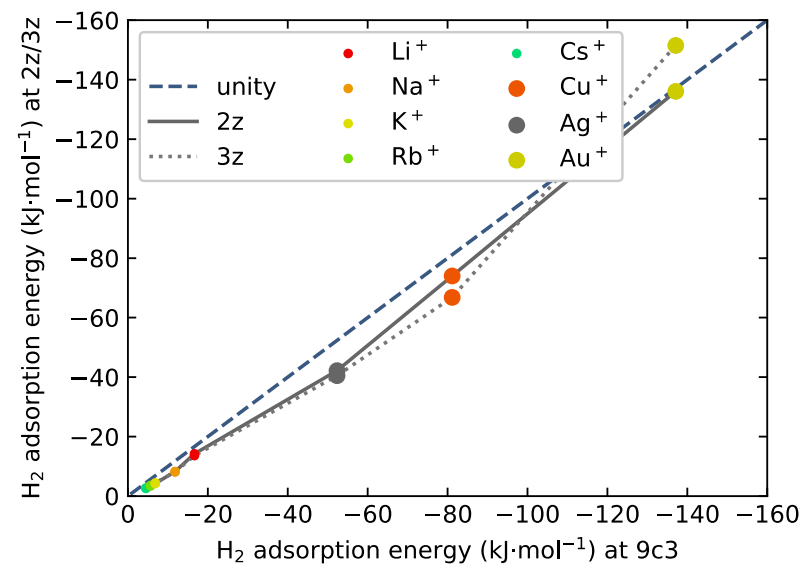

Figure S2. Correlation of the $\mathrm{H}_{2}$ adsorption at 9-crown-3 and the zeolite cluster models.
Influence of the frozen adsorption-site approach on the zero-point energy of adsorbed $\mathrm{H}_{2}$

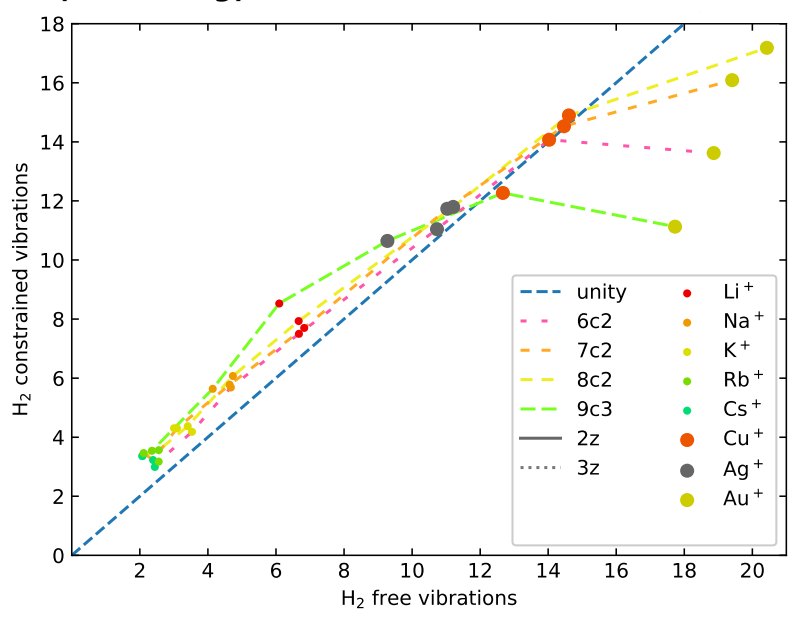

Figure S3. Comparison of the zero-point vibrational energy $\left(\mathrm{kJ} \cdot \mathrm{mol}^{-1}\right)$ calculated ( $x$ axis) with full relaxation and full analytic harmonic vibrational frequency analysis and $(y)$ with rigid crown-ether (including the metal cation), relaxation only of the adsorbed molecule and partial numerical vibrational frequency analysis.

\section{Beyond $\mathrm{H}_{2}$ adsorption}

Both $\mathrm{CO}$ and ethene adsorb significantly more strongly than $\mathrm{H}_{2}$ giving them the potential to influence the geometry of the adsorption site more strongly. For example, $\mathrm{CO}$ is known to favor $2 \mathrm{z}$-like environments and to distort $3 \mathrm{z}$ like structures into $2 \mathrm{z}$-like ones to accommodate for this preference (Bludsky2005, 10.1016/j.cattod.2004.09.070, Bolis2004, 10.1021/jpo49613e). Since a thorough examination of this effect is beyond the scope of this article, we take the similarity between the results from the $2 \mathrm{z}$ and $3 \mathrm{z}$ models as an indication that both can serve as reasonable zeroorder benchmarks to compare the crown-ether complexes against. 


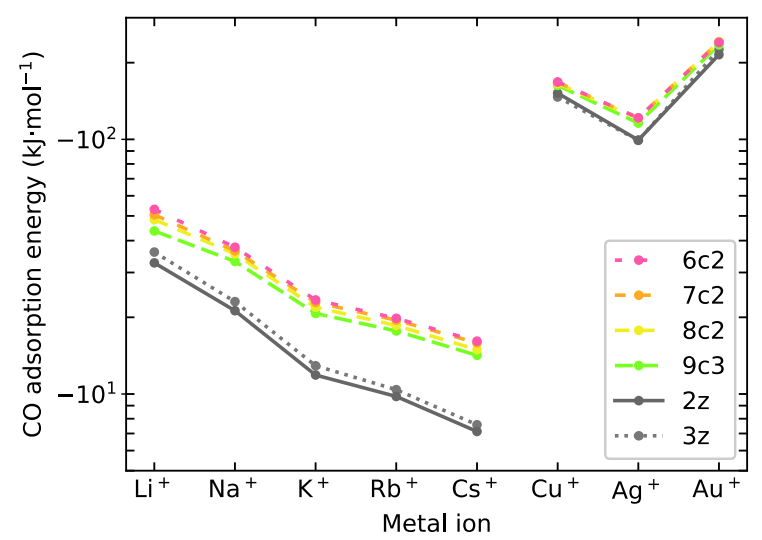

Figure $\mathrm{S}_{4}$. $\mathrm{CO}$ adsorption energy as function of the metal ion.

Overall, $\mathrm{CO}$ and ethene adsorption energies at crownether complexes are similar to those at the zeolite cluster models. A good correlation is also found for the $\mathrm{C}=\mathrm{C}$ stretch frequencies of ethene. For $\mathrm{C}=\mathrm{O}$ stretch frequencies, crown-ethers show the same tendencies as zeolites, albeit big quantitative differences probably preclude any useful application of the analogy for $\mathrm{CO}$.

\section{CO adsorption}

Unlike $\mathrm{H}_{2}$, $\mathrm{CO}$ coordinates to the cations end-on via the carbon atom. As in the case for $\mathrm{H}_{2}$, adsorption energies are similar for the crown-ether and the zeolite models (see Figure $\mathrm{S}_{4}$ ). Coordination is dominated by $\sigma$ donation as shown by the $\mathrm{C}=\mathrm{O}$ bond lengths and stretch frequencies, which differ from the value of the free molecule by less than $1 \mathrm{pm}$ and $90 \mathrm{~cm}^{-1}$, respectively.

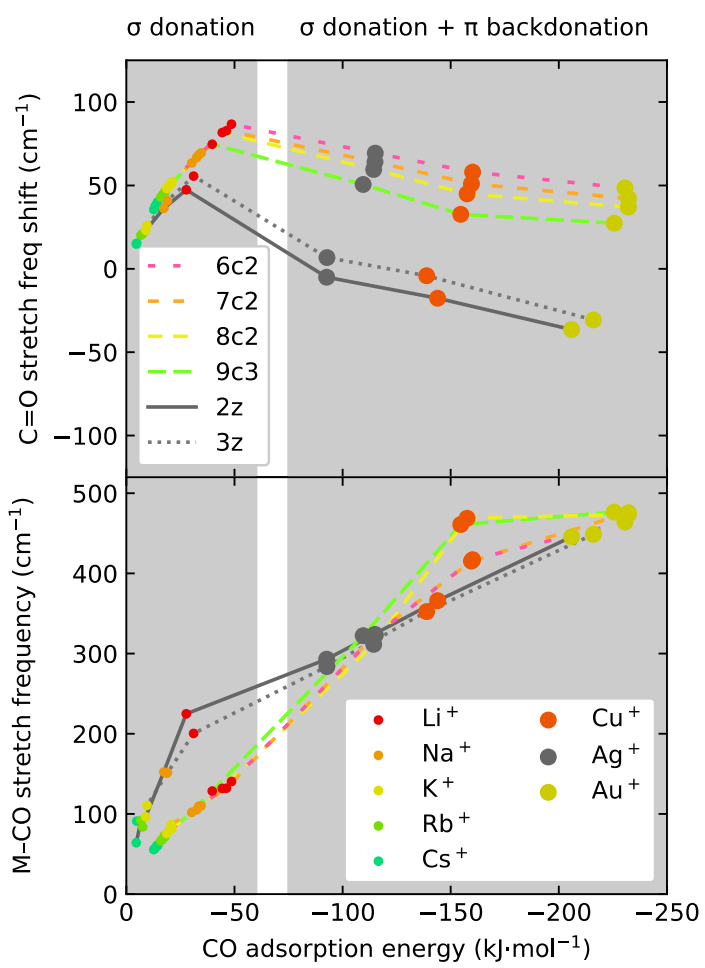

Figure $\mathrm{S}_{5}$. Correlation of the $\mathrm{C}=\mathrm{O}$ stretch frequency, $v_{\mathrm{CO}}$, and the $\mathrm{M}-\mathrm{CO}$ stretch frequency, $v_{\mathrm{M}-\mathrm{CO}}$, with the adsorption energy of $\mathrm{CO}$.

Figure $\mathrm{S}_{5}$ shows how the $\mathrm{C}=\mathrm{O}$ stretch frequency correlates with the adsorption energy of $\mathrm{CO}$. The complex relationship is explained by the fact that the $\mathrm{C}=\mathrm{O}$ stretch frequency, $v_{\mathrm{CO}}$, of carbonyl ligands is determined by the interplay of $\sigma$ donation (which reduces electron density on the carbon and thereby strengthens the $\mathrm{C}=\mathrm{O}$ bond) and $\pi$ backdonation (which increases electron density in the anti-bonding $\mathrm{C}=\mathrm{O} \pi$ orbitals and weakens it). Since alkali cations cannot partake in $\pi$ backdonation due to lack of valence $d$ orbitals, $v_{\mathrm{CO}}$ increases with increasing adsorption energy for these ions. By contrast, the low oxidation states of the coinage metal ions lead to a strong $\pi$ backdonation and therefore lower $v_{\mathrm{CO}}$. Although both types of models share this property, the effect is stronger for zeolite models than for the crown-ethers due to the net positive charge of the latter. Overall, the quantitative differences are too pronounced to consider crown-ether complexes suitable model systems for adsorption sites in zeolites when employing the $\mathrm{C}=\mathrm{O}$ stretch frequency as characteristic feature. 
By contrast, $v_{\mathrm{M}-\mathrm{co}}$ shows a direct positive (albeit not linear) correlation with the $\mathrm{CO}$ adsorption energy. It might therefore serve as a more suitable measure of the strength of the $\mathrm{CO}$ adsorption.

\section{Ethene adsorption}

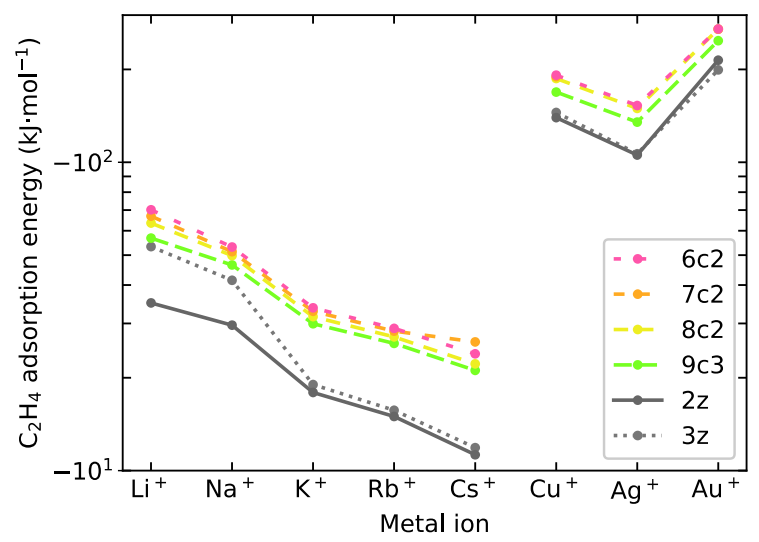

Figure S6. Adsorption energy of ethene as a function of the metal ion.

Ethene combines a strong interaction like the one observed for $\mathrm{CO}$ with the side-on coordination mode seen in $\mathrm{H}_{2}$. Figure $\mathrm{S} 6$ shows the trends of the ethene adsorption energies along the periodic table. Similar to what is observed in both $\mathrm{H}_{2}$ and $\mathrm{CO}$, the crown-ether molecules follow the same trend as the zeolite clusters. What sets ethene apart is its $\pi$ electron system, which makes it a stronger Lewis base. Of the three gas molecules, it therefore shows the strongest preference for crown-ethers vs zeolites, because their net positive charge makes the former the stronger Lewis acids.

The most characteristic and accessible vibrational mode of ethene is the $C=C$ stretch vibration. Figure $S_{7}$ shows the strong correlation of the corresponding vibrational frequency between ethene bound at 9-crown-3 and ethene bound at the $2 \mathrm{z}$ zeolite cluster model. This correlation breaks down only for gold, which is predicted to interact more strongly than the other metal ions examined.

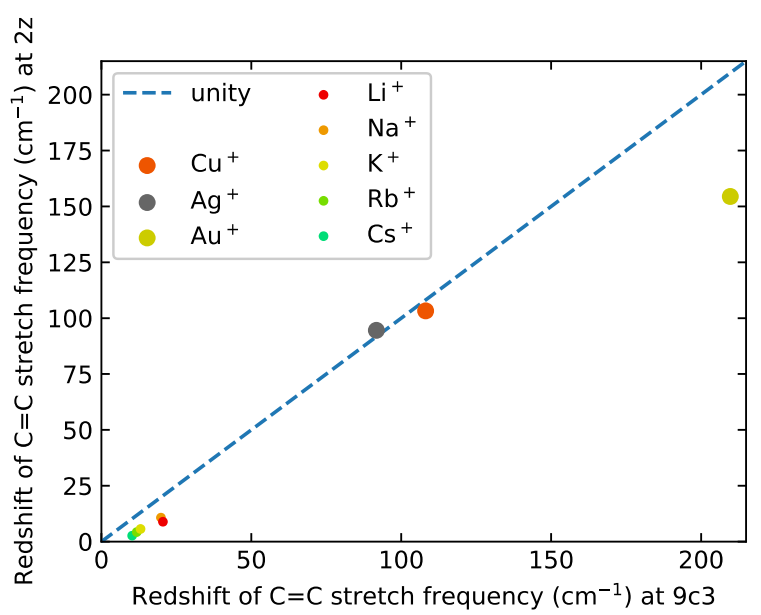

Figure $\mathrm{S}_{7}$. Correlation of the $\mathrm{C}=\mathrm{C}$ stretch frequency between 9-crown- 3 and the $2 \mathrm{z}$ zeolite model. 